\title{
Uma discussão sobre a utilidade do design através do foco emocional
}

INICIAÇÃO CIENTÍFICA

\author{
A discussion about the design utility \\ through the emotional focus
}

Rômulo Linhares de Oliveira

http://lattes.cnpq.br/0916978621671812

Karina Pereira Weber [orientadora] http://lattes.cnpq.br/5493103088912010

\section{Resumo}

O presente artigo tem como objeto discutir como o design emocional interfere na vida do ser humano diariamente e em suas relações interpessoais e com o ambiente que o cerca. Será feita uma reflexão sobre onde se pode encontrar o design e como a vida das pessoas se tornaria sem essa atividade. Esse trabalho irá abordar questões como a função dos produtos (prática, estética e simbólica) e que tipo de relação esses produtos mantêm com o seu usuário. O trabalho será apresentado através de um foco simbólico e emocional para que, ao final, seja possível estabelecer um diálogo sobre a utilidade do design.

\section{Palavras-chave}

Design Emocional. Design Simbólico. Utilidade.

\section{Abstract}

The actual paper aims to discuss how the emotional design affects our daily life, our interpersonal relationships and how we interact with the environment around us. At a first moment, this work will reflect about where we can find "design" how the our lives would be without it. It will also approach matters like the function of products and what kind of relationship they establish with their users. The work will be presented through a symbolic and emotional focus, so at the end of it we can dialogue about the utility of design.

\section{Keywords}

Emotional Design. Symbolic Design. Utility.

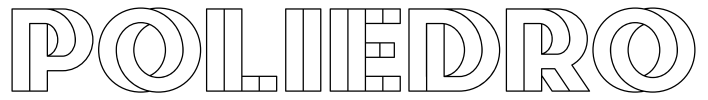




\section{Introdução}

Você já imaginou viver em um mundo essencialmente funcional, sem cores, sem formas atraentes, sem diversão ou emoção? Esse seria um mundo sem a atividade do design, como afirma Bürdeck (2006):

\footnotetext{
A vida da maioria das pessoas não é mais imaginável sem o Design. O Design nos segue de manhã até a noite: na casa, no trabalho, no lazer, na educação, na saúde, no esporte, no transporte de pessoas e bens, no ambiente público - tudo é configurado de forma consciente ou inconsciente. Design pode ser próximo da pele, (como na Moda) ou bem afastado (como no caso do uso espacial). Design não apenas determina nossa existência, mas neste meio tempo nosso próprio ser. Por meio dos produtos nos comunicamos com outras pessoas, nos definimos em grupos sociais e marcamos cada vez nossa situação social (BÜRDECK, 2006, p. 14).
}

Silva e Cavalcanti (2015) nos dizem que somos bombardeados com informações visuais que compõem nosso ambiente diariamente: móveis, cartazes, roupas, objetos diversificados dispostos de acordo, ou não, com a nossa vontade e satisfação, o que pode interferir em nosso humor, decisões e relações interpessoais. Frascara (2004, apud MENEZES, 2007) explica que os objetos que estão ao nosso redor representam uma extensão de quem somos, de como queremos ser percebidos e de como expressamos sentimentos pelas pessoas, por nós mesmos e por esses objetos. Desse modo, fica claro que não compramos um telefone celular apenas para fazer ligações ou uma roupa para proteger nossa pele e sim para representar diversos sentidos e funções como a autossatisfação de possuir algo ou de explicitar nossa personalidade através do que usamos e possuímos.

Ainda, de acordo com ideias de Silva e Cavalcanti (2015), o design é responsável, dentre outras tarefas, pelas relações entre homem e objeto; em outras palavras, ele determina como nos relacionamos com o ambiente à nossa volta, com outras pessoas e com nós mesmos. Esses objetos estão sempre em constante transformação e o que determina essa mudança de forma segundo Petroski (2007), é o nosso desejo. Por exemplo: claramente necessitamos de condições básicas de sobrevi- 
vência como alimentação, hidratação e abrigo, porém não precisamos da gastronomia, água gelada ou de casas cada vez mais modernas e ricas em arquitetura. Pode-se dizer, então, que a busca pelo luxo, prazer e satisfação pessoal são as forças motrizes que geram a invenção.

Bonsiepe (1997) reforça as ideias dos autores citados anteriormente dizendo que o design é o responsável pela interação entre o homem e o objeto e acrescenta que ele é um meio para se realizar uma tarefa de modo efetivo. Para ele, o design não se resume em projetar as funcionalidades de um produto, pois acredita que outras áreas são responsáveis por isso como a engenharia e outros campos; portanto o autor define todo e qualquer design como sendo um design de interfaces que faz intermediação entre a relação do usuário com o ambiente em que ele está inserido. Esse sistema é composto por um agente social ou usuário que deseja praticar uma ação com eficiência como, por exemplo, escutar música, através de uma ferramenta que pode ser exemplificada com um celular que reproduza arquivos mp3 ou outros formatos de arquivos de áudio. Desse modo, temos três elementos: um usuário, uma tarefa e um artefato ou ferramenta; esses três elementos são unidos através de uma interface sendo que essa não é "uma coisa, mas o espaço no qual se estrutura a interação entre o corpo, ferramenta (objeto ou signo) e o objetivo da ação" (BONSIEPE, 1997, p. 16).

Levando em consideração esses conceitos, abordarei aqui, o design centrado no usuário sendo analisado como uma experiência emocional e simbólica. Para isso, a seguir serão apresentadas as funções dos produtos e objetos.

\section{Funções dos produtos}

Löbach (2001) nos diz que cada produto pode apresentar funções diferentes de acordo com o propósito para o qual foram projetados, promovendo assim diferentes tipos de interação e provocando diversas emoções que diferem de usuário para usuário.

Os prazeres podem ser também proporcionados pelos objetos que nos cercam. Durante muitos séculos, os seres humanos têm criado objetos funcionais e decorativos em busca de prazeres. Esses prazeres estão 
De acordo com Löbach (2001) as funções dos produtos são classificadas como: função prática, função estética e função simbólica. A função prática, como o nome já sugere, é centrada usabilidade de cada objeto e suas funcionalidades, estabelecendo assim, uma relação fisiológica com o usuário. A função estética está relacionada com a configuração das formas de cada objeto; ela estabelece uma relação de percepção sensorial entre o usuário e o objeto. A função simbólica está relacionada com experiências e sensações que o objeto provoca no usuário; estabelece relações sociais e psíquicas entre o objeto e o usuário.

Já Norman (2008) trata o mesmo assunto de uma maneira um pouco distinta sob o viés do design emocional. Ele classifica o design através das seguintes definições:

A) Design visceral: está relacionado à aparência dos objetos; o impacto visual que o objeto causa atua diretamente na relação de afeto com o seu usuário. Podemos compará-lo à função estética de Löbach (2001). A seguir, a Figura 1 ilustra o design visceral:
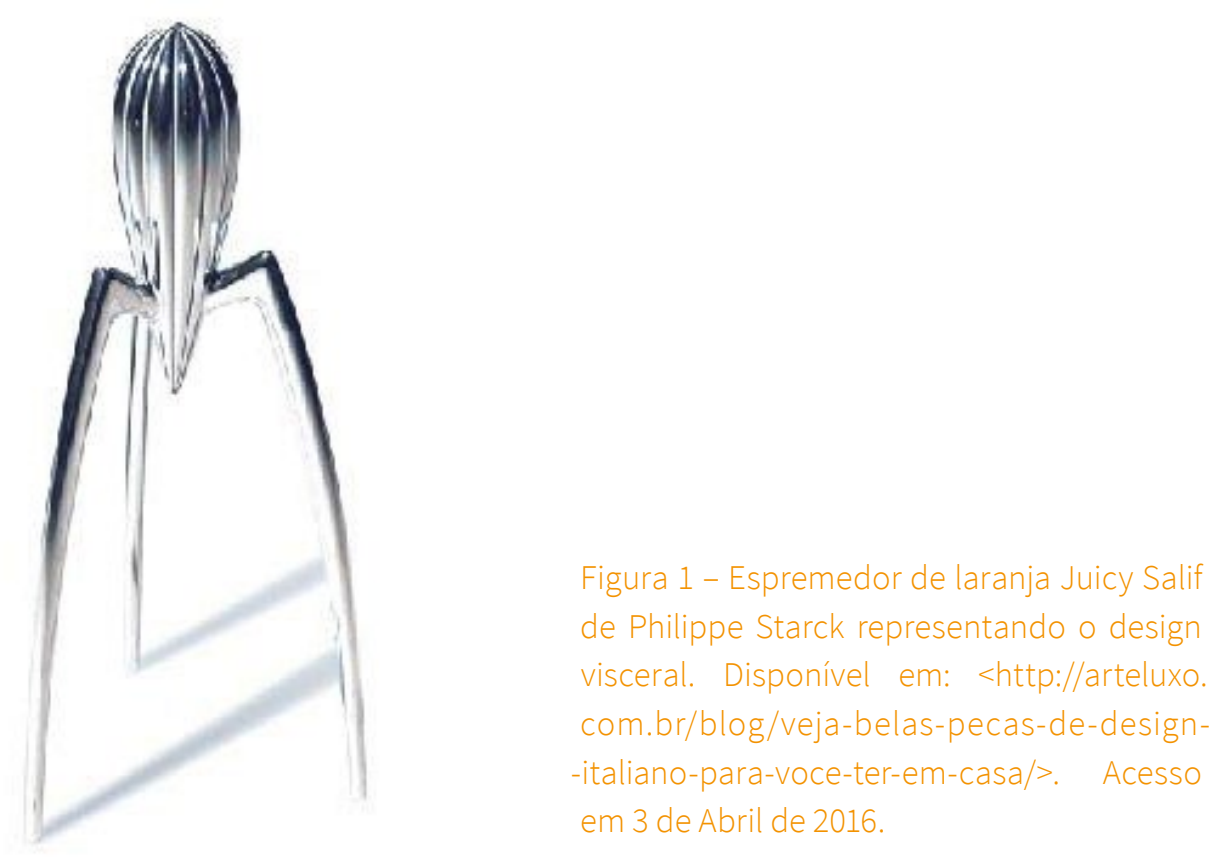
B) Design comportamental: está relacionado com a experiência de compreensão do produto e de suas funcionalidades; se preocupa com o desempenho dos objetos em relação à sua forma. Podemos compará-lo à função prática de Löbach (2001). A seguir, a Figura 2 ilustra o design comportamental:

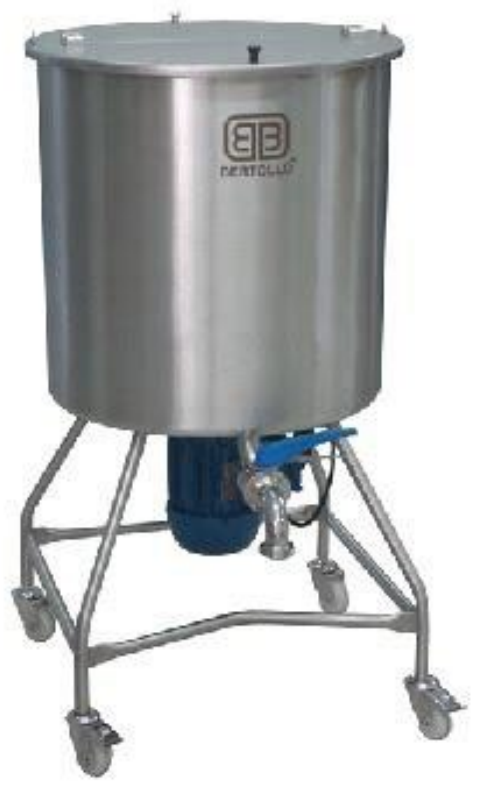

Figura 2 - Liquidificador industrial Bertollo representando o design comportamental. Disponível em: < httpbertollo.com.br2014inicio.phparea=catalogo>. Acesso em 3 de Abril de 2016.

C) Design reflexivo: está intimamente relacionado com as emoções do usuário. Se preocupa com a relação de afeto e prazer por se ter determinado objeto, com a memória e experiências de vida do usuário e com o que o indivíduo que os possui quer comunicar aos outros e a si mesmo. Podemos compará-lo com a função simbólica de Löbach (2001). A seguir, a Figura 3 ilustra o design reflexivo: 


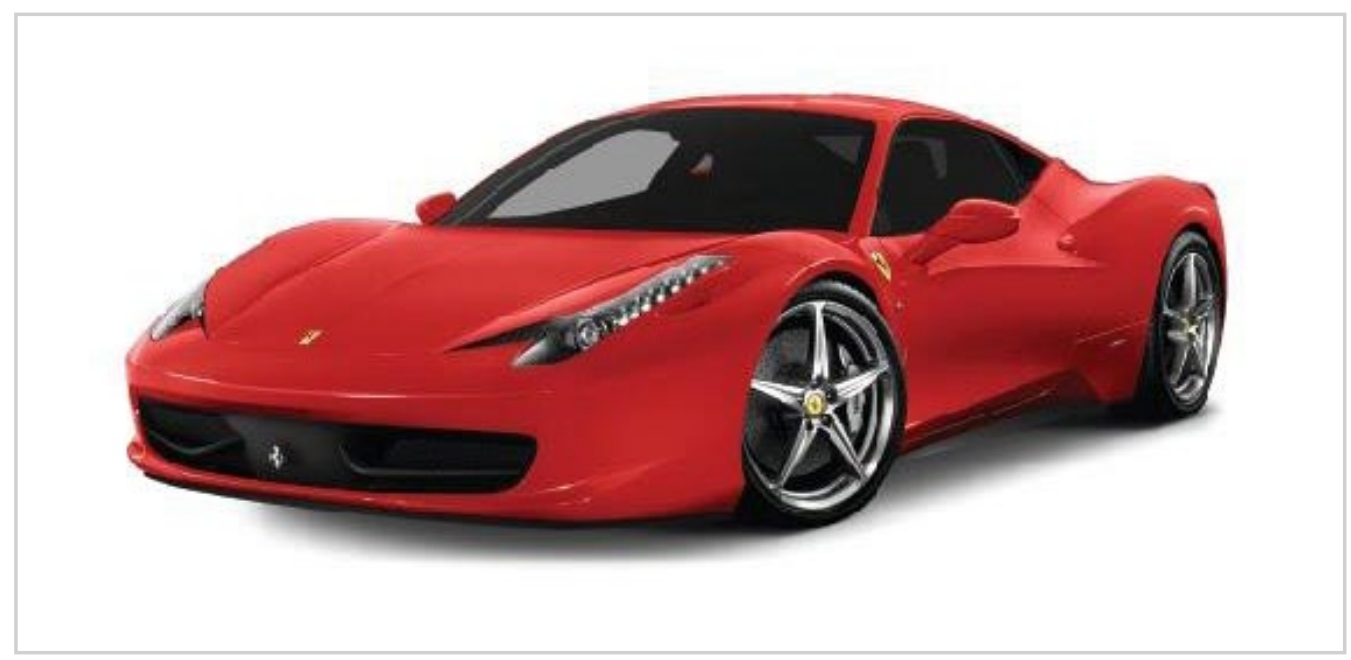

Figura 3 - Ferrari representando o design reflexivo. Disponível em: < http://www.autoblog.com/ car-finder/ferrari/>. Acesso em 3 de Abril de 2016.

Portanto, a meu ver, não existe design emocional se ignorarmos qualquer uma dessas três classificações, porém ele está mais atrelado ao design visceral e reflexivo, principalmente a esse último. Então, no tópico a seguir falarei mais detalhadamente sobre design emocional para explicar sua relação com essas funções dos produtos ou classificações de design.

\section{Design emocional}

Para começar a tratar do assunto "design emocional", apresento aqui as ideias de Cantelli (2009) que afirma que qualquer experiência que envolva emoções é gravada na memória afetiva de cada pessoa criando uma relação das vivências passadas com atividades do cotidiano. $A$ partir disso, a emoção provoca diferentes ações em cada indivíduo de acordo com a percepção de cada um e com o sentimento gerado pelo cérebro. São as conhecidas "atitudes emocionais".

O design emocional é totalmente centrado no usuário, pois de acordo com Freire (2009) o usuário passou a ser uma figura de suma importância no processo de design quando suas necessidades se modificaram e o foco dos projetos passou a ser a experiência de uso e o que esse uso provoca em cada indivíduo. Os autores Silva e Martins (2013) afirmam que a interdisciplinaridade é fundamental ao exercício do design emocional ao dizer que 


\section{$<$ aliado aos estudos e pesquisas de áreas que o complementam e que o orientam, o design emocional trabalha com a perspectiva de que a emoção pode ser, no mínimo, previsível. Com efeito, o design emocio- nal dialoga com a filosofia, a psicologia, a sociologia, as análises do dis- curso, etc. (SILVA; MARTINS, 2013, p. 3).}

Portanto, é indispensável conhecer o perfil de cada usuário, suas necessidades fisiológicas e psicológicas e sua identidade para que seja possível prever desejos e, desse modo, criar produtos munidos de significados particulares e emocionais de acordo com cada pessoa que desencadeiem atitudes dotadas de sentimentos e que levem à aquisição desse objeto. Cantelli (2009) afirma que o objetivo do design emocional não é apenas criar um produto funcional que seja esteticamente atrativo e sim estimular vínculos afetivos, subjetivos e simbólicos entre o usuário e o objeto.

Silva e Cavalcanti (2015) desenvolveram uma ferramenta chamada MADE (Modelo de Análise do Design Emocional) que como eles afirmam é "uma síntese das diversas formas de interação entre objetos e indivíduos" (SILVA; CAVALCANTI, 2015, p. 11). Dentre as diversas abordagens que o MADE nos apresenta, ele chega à conclusão que design emocional está relacionado com os sentimentos mais intensos que o artefato desperta em quem interage com ele. Sendo assim, o design emocional é o responsável por amarmos ou odiarmos um produto.

Concluo esse parágrafo com uma última citação de Silva e Martins (2013) que afirmam que

$<<$ o design emocional não tem como objetivo manipular ou controlar as emoções do usuário, na verdade trabalha interpretando os desejos e o que leva uma pessoa a consumir através da emoção. E isso se desenvolve através de estudos e pesquisas no sentido de concretizá-los em forma de produtos que correspondam às necessidades emocionais dos indivíduos que devem estar contempladas no artefato projetado (SILVA; MARTINS, 2013, p. 3). 
Após apresentadas as funções dos produtos e abordar aspectos simbólicos e emocionais do design, chego à principal pergunta desse artigo: o design possui um propósito real ou é apenas uma atividade vazia?

\section{Utilidade do design}

Portugal (2013) reafirma o que outros autores já citados aqui defendem: que o design é uma atividade que atua modificando a forma dos artefatos e objetos em geral com um outro objetivo que não atrelado à funcionalidade desses produtos criados. Ele defende em seu texto que "para adequar um objeto àquilo que consideramos sua função específica, seria melhor servir-se de uma atividade sustentada por saberes específicos sobre o objeto em questão" como, por exemplo, a relojoaria e os relógios produzidos por ela (PORTUGAL, 2013, p. 53). Portanto, se a utilidade dos objetos for sinônima de função específica, obviamente o design é uma atividade inútil, porém isso não quer dizer que ele não possua outras finalidades, uma vez que a forma projetada passa a ser um grande potencial comunicativo. Desse modo, é extremamente importante conhecer a potência de comunicação das formas, pois é exatamente isso que sustenta a atividade do design, apesar de ser uma tarefa bastante difícil por lidar com os mais diversos significados e contextos existentes. De acordo com o autor, se pensarmos o design como uma atividade comunicativa podemos concluir que ele é útil quando essa comunicação possui um objetivo específico como "vender produtos".

Embora esta dimensão seja, sem dúvida, muito importante, talvez não estejamos errados em pensar que a forma de comunicação mais importante para nós, enquanto humanos, é uma comunicação essencialmente inútil (...) cujo fim principal é sustentar pactos e vínculos - não apenas com os outros, mas também com nós mesmos, pois aquilo que chamamos de "eu" talvez não seja mais que um conjunto formado pelo vínculo precário de diversos impulsos, pensamentos, desejos, sensações, afetos, etc. (PORTUGAL, 2013, p. 55).

Ainda levando em consideração o que Portugal (2013) nos diz, o design estabelece uma relação de comunicação entre homem e objeto 
sem nenhuma finalidade externa à própria comunicação; o importante é que esse objeto crie um vínculo com o usuário afetando o modo de vida dele e, por conseguinte, afetando a relação com outras pessoas e objetos ao seu redor. $O$ autor considera o design inútil sob esse ponto de vista, pois afirma que tudo o que consideramos útil são instrumentos que servem como um meio para se realizar qualquer atividade externa a eles. Entretanto, ele afirma que "coisas que são desejadas por si mesmas, e que são, portanto, inúteis - já que não servem a nenhum fim externo a elas -, são as mais importantes" (PORTUGAL, 2013, p. 58).

\section{Considerações finais}

Vimos até aqui que o design é uma atividade essencialmente comunicativa que atua modificando as formas dos objetos, alterando assim o ambiente em que estamos inseridos. Também vimos que os produtos apresentam diferentes funções de acordo com as necessidades de cada usuário e que o design emocional trata de prever desejos e necessidades psicológicas e simbólicas dos usuários tentando projetar objetos que possam estabelecer um vínculo afetivo com seu usuário. Percorremos todo esse caminho para tentar responder a pergunta "o design é útil?" procurando fugir da abordagem funcional do design. Logo, vimos que o autor Portugal (2013) trata a inutilidade emocional do design como sendo mais importante que sua utilidade funcional, por adquirirmos produtos por eles mesmos sem termos interesse em utilizá-los para outros fins. Portanto, o design emocional é inutilmente útil para a nossa vida em sociedade, para nosso bem-estar e para a formação de nossa identidade pessoal.

Encerro esse trabalho com uma citação de Lipovetsky (2014, p. 253): "O ideal do design não é mais a racionalidade funcional ou objetiva, mas a experiência sensorial, a amenidade dos objetos e do ambiente, a melhoria do bem-estar e das qualidades percebidas". 


\section{Referências}

BÜRDECK, Bernhard E. História, teoria e prática do

design de produtos. São Paulo: Edgard Blücher, 2006.

BONSIEPE, Gui. Design do material ao

digital. Florianópolis: FIESC/IEL, 1997.

CANTELLI, Ana Paula. Design Emocional. In:

SICITE - UTFPR; XIV Seminário de Iniciação Científica

e Tecnológica da UTFPR, 2009, Pato Branco.

FREIRE, Karine. Reflexões sobre o conceito de design

de experiências. Reflections upon the experience design concept. Strategic Design Reserach Journal: 2009.

LÖBACH, Bernd. Design Industrial. São Paulo: Blücher, 2001.

LIPOVETSKY, Gilles. A estetização do mundo: viver na era do capitalismo artístico. São Paulo: Companhia das Letras, 2015. Tradução de: Eduardo Brandão.

NORMAN, Donald A. Design Emocional: por que adoramos (ou detestamos) os objetos do dia-a-dia. Rio de Janeiro: Rocco, 2008.

PETROSKI, Henry. A evolução das coisas úteis:

clipes, garfos, latas, zíperes e outros objetos do nosso cotidiano. Rio de Janeiro: Jorge Zahar Ed., 2007.

PORTUGAL, Daniel B. Existe Design?: Indagações

filosóficas em três vozes. Teresópolis: 2ab, 2013. 
SILVA, Maria de Fatima; MARTINS, Marcelo Machado. DESIGN E EMOÇÃO: novos modos de vida, novas reconfigurações de objetos e valores. 2013. Disponível em: <http://www.coloquiomoda. com.br/anais/anais/9-Coloquio-de-Moda_2013/ARTIGOS-DE-GT/ Artigo-GT-Consumo-de-Moda/DESIGN-novos-modos-de-vida-novasreconfiguracoes-de-objetos-e-valores.pdf>. Acesso em 02 abr. 2016.

SILVA, Washington Ferreira; CAVALCANTI, Virginia Pereira. Modelo de análise de design emocional aplicado ao desenvolvimento de produtos de moda. 2015. Disponível em: <http://www.coloquiomoda. com.br/anais/anais/11-Coloquio-de-Moda_2015/ARTIGOS-DE-GT/GT04DESIGN-E-PROCESSOS-DE-PRODUCAO-EM-MODA/GT-4-MODELODE-ANALISE-DO-DESIGN-EMOCIONAL.pdf>. Acesso em: 02 abr. 2016 